\title{
Caracterização de rebanhos leiteiros da raça Girolando através da tipificação de marcadores moleculares para kappa-caseína
}

\author{
Characterization of dairy herds Girolando through typification of molecular markers \\ for kappa-caseína
}

\author{
BARBOSA, Severino Benone Paes ${ }^{1}$; REZENDE, Fábio Monteiro de ${ }^{2}$; FREITAS, \\ Soraya Farias de Andrade $^{3}$; GOMES FILHO, Manoel Adrião ${ }^{4}$; SILVA, Catarina Xavier \\ $\mathrm{da}^{5}$; SANTORO, Kleber Régis ${ }^{6}$; SILVA, Regina Cely Benício da ${ }^{1}$
}

\footnotetext{
${ }^{1}$ Universidade Federal Rural de Pernambuco, Departamento de Zootecnia, Recife, Pernambuco, Brasil.

${ }^{2}$ Universidade Federal Rural de Pernambuco, Programa de Pós-Graduação em Zootecnia, Recife, Pernambuco, Brasil.

${ }^{3}$ Universidade Federal do Amazonas, Parintins, Amazonas, Brasil.

${ }^{4}$ Universidade Federal Rural de Pernambuco, Departamento de Morfologia e Fisiologia Animal, Recife, Pernambuco, Brasil.

${ }^{5}$ Universidade Federal Rural de Pernambuco, Recife, Pernambuco, Brasil.

${ }^{6}$ Universidade Federal Rural de Pernambuco, Unidade Acadêmica de Garanhuns, Garanhuns, Pernambuco, Brasil.

*Endereço para correspondência: sbarbosa@dz.ufrpe.br
}

RESUMO

Objetivou-se caracterizar o genótipo da kappacaseína em 144 vacas Girolando, do Estado de Pernambuco, utilizando a técnica de PCR-RFLP. Foram coletadas amostras de sangue total desses animais dos seguintes grupos genéticos: 30 1/2 holando-gir, 38 3/4 holando-gir e 76 5/8 holandogir. Desse material foi extraído o DNA. Através do DNA foi determinada uma região que foi amplificada e seu produto sofreu ação da enzima de restrição HindIII para observar os possíveis polimorfismos. Foram encontrados os seguintes genótipos com respectivas frequências: AA $(0,59)$; $\mathrm{AB}(0,25)$ BB $(0,06) ; \mathrm{AC}(0,05) ; \mathrm{BC}$ $(0,02)$ e CC $(0,02)$. As frequências alélicas observadas para os genes $\mathrm{A}, \mathrm{B}$ e $\mathrm{C}$ foram 0,74 ; 0,20 e 0,06 , respectivamente. Há de se registrar a detecção do gene $C$ na população, raramente descrito em outros trabalhos. A presença do genótipo BB na população de vacas holando-gir aponta para implantação de programas de seleção genética visando aumento na frequência do genótipo em questão, o que possibilitará ganhos significativos na cadeia do leite, particularmente, para produtores e indústrias de processamento.

Palavras-chave: PCR/RFLP, polimorfismo, proteínas lácteas, qualidade do leite

\section{SUMMARY}

This study aimed to characterize the genotype of kappa-casein in 144 Gir cows, the State of Pernambuco, using PCR-RFLP. 30 1 12 Holsteingir-gir 38 3/4 Holstein and Holstein-turned 76 5\%: Whole blood samples of the animals of the following genotypes were collected. This material was extracted DNA. Through a region of DNA was amplified and its product has the action of restriction enzyme HindIII possible to observe the polymorphism was determined. The following genotypes with respective frequencies were found: $\mathrm{AA}(0.59)$; $\mathrm{AB}(0.25) \mathrm{BB}(0.06)$; CA (0.05); BC (0.02) and CC (0.02). The allele frequencies observed for genes $\mathrm{A}, \mathrm{B}$ and $\mathrm{C}$ were $0.74 ; 0.20$ and 0.06 , respectively. Important to note the detection of the $\mathrm{C}$ gene in the population, rarely described in other papers. The presence of the BB genotype in the population of Holstein cows-turned points for deployment of genetic selection for increased frequency of the genotype in question, which will enable significant gains in the milk chain, particularly for producers and processing industries programs.

Keywords: kappa-casein, molecular markers, PCR/RFLP, polymorphism 
Rev. Bras. Saúde Prod. Anim., Salvador, v.16, n.1, p.- jan./mar., $2015 \quad$ http://www.rbspa.ufba.br ISSN 15199940

\section{INTRODUÇÃO}

A indústria do leite tem se baseado em identificar uma eficiente e econômica via para o aumento da produção de leite e de seus constituintes. A seleção de animais com genótipos desejados e a manutenção deles para reprodução das próximas gerações tem sido a base para a sustentabilidade e eficiência desta indústria (RACHAGANI et al., 2006). A aplicação da seleção assistida por marcadores tem sido uma ferramenta eficaz no melhoramento dos animais e sua utilização implica no conhecimento do genótipo do animal e aumenta a acurácia de sua avalição, possibilitando maior progresso genético por geração, a partir da redução do intervalo de gerações.

O uso de características qualitativas, como tipo de proteínas do leite, pode ser excelente ferramenta como marcador auxiliar de seleção em programas de melhoramento, resultando em alterações significativas no leite. Estas variantes protéicas possuem diferentes composições químicas e se identificam por sua mobilidade eletroforética, refletindo a ação de genes autossômicos transmitidos dos pais para a prole por herança mendeliana simples.

A kappa-caseína (k-Cn) é essencial para formação e estabilização das micelas e tem um efeito importante sobre as propriedades do leite (TSIARAS et al., 2005). Diversos polimorfismos têm sido descritos para o gene da k-Cn, tanto na região codificadora quanto na promotora. Recentemente, foram descobertos os alelos $\mathrm{C}$ e $\mathrm{E}$, mais raros, em muitas raças (ERHARDT \& SENFT, 1989).

Para identificação de certos caracteres, pode-se recorrer à técnica de RFLP (restriction fragment length polymorfism) que se baseia na presença de sítios de restrição na região amplificada do DNA-molde que pode ser determinada por intermédio do processamento do produto da PCR (polymerase chain reaction), com uma ou mais endonucleases de restrição (GARCIA, 1995).

A maioria dos trabalhos realizados nessa área foi com bovinos holandeses e mestiços em diversos países (COMIN et al., 2008). No Brasil, a base da bovinocultura de leite são todos os grupos genéticos do cruzamento holando-gir, inclusive o grupamento $5 / 8$ que foi fixado como a raça sintética Girolando. Já o interesse da indústria por leite desses animais se resume a seus altos teores de sólidos, quando comparados com animais de raças especializadas.

Dessa forma, objetivou-se com este trabalho caracterizar o genótipo da kappa-caseína em vacas Girolando de três grupos genéticos, utilizando a técnica de PCR-RFLP.

\section{MATERIAL E MÉTODOS}

O trabalho foi desenvolvido no Laboratório de Fisiologia Animal e Morfologia Aplicada da Universidade Federal Rural de Pernambuco. Foram utilizados 144 animais, sendo 30 1/2 holando-gir, 38 3/4 holando-gir e 76 5/8 holando-gir, oriundos de duas fazendas particulares e de duas fazendas experimentais, essas últimas pertencentes ao IPA (Instituto Agronômico de Pernambuco), localizadas nas regiões da Zona-da-Mata Norte e Agreste Central e Agreste Meridional, do Estado de Pernambuco.

Foram colhidas amostras de $10 \mathrm{ml}$ de sangue total (tubos para coleta de sangue a vácuo contendo EDTA), de fêmeas cruzadas Holando-Gir, clinicamente sadias, criadas de maneira semi-intensiva, provenientes de propriedades localizadas na bacia leiteira do Estado de 
Rev. Bras. Saúde Prod. Anim., Salvador, v.16, n.1, p.- jan./mar., $2015 \quad$ http://www.rbspa.ufba.br ISSN 15199940

Pernambuco, região da Zona-da-Mata e Agreste.

As amostras foram acondicionadas imediatamente em recipiente contendo gelo. Os leucócitos foram obtidos por centrifugação (3000 rpm por $10 \mathrm{~min}$ ) e lavados com solução salina $(0,9 \%$ em $\mathrm{NaCl}$ ), repetida por três vezes, até as células (eritrócitos e leucócitos) estarem bem lavadas. Em seguida, com auxílio de uma pipeta, a camada das células brancas foi aspirada, para ser acondicionada em tubo eppendorf de $1,5 \mathrm{ml}$ e armazenada a $-20^{\circ} \mathrm{C}$.

A extração do DNA leucocitário foi realizada através do método descrito por Maniatis et al. (1989). O DNA extraído foi analisado e quantificado no espectrofotômetro. Um amostra desse DNA foi avaliada através de uma corrida de eletroforese em gel de agarose a $0,8 \%$, corado com brometo de etídeo. A visualização das bandas foi feita através de luz ultravioleta e fotografadas para verificação de sua qualidade.

Após extração do DNA, as amostras foram padronizadas quanto a concentração. Para isso um espectrofotômetro foi utilizado para fazer a dosagem de DNA. Uma concentração padrão de $50 \mathrm{ng} / \mu \mathrm{l}$ foi estipulada em um volume de $20 \mu \mathrm{l}$ para todas as amostras a fim de se ter uma quantidade padronizada de DNA extraído nas reações de PCR.

As reações de amplificação foram realizadas em um volume final de $25 \mu 1$. Cada reação foi constituída de $4,5 \mu \mathrm{l}$ de $\mathrm{MgCl}_{2}, 2 \mu \mathrm{l}$ (100ng) do DNA, 0,5 $\mu \mathrm{l}$ do Primer A e 0,5 $\mu$ l do Primer B (usa-se um Primer específico para cada Loci), 2,5 $\mu 1$ de DNTP, $2,5 \mu 1$ de Tampão, $0,1 \mu l$ ( 2 unidades) da enzima Taq DNA polimerase e $12,4 \mu$ l de água ultra pura. As reações foram efetuadas em um termociclador (Termociclador Eppendorf Mastercycler personal). Para as amplificações por PCR do lócus do terceiro exon do gene da kappacaseína (CSN3), entre os nucleotídeos 10592 e 11466 desse gene (ALEXANDER et al., 1988), foi utilizado o seguinte oligonucleotídeo:

\section{A 5'-GTGCTGAG(T/C)AGGTATCCTAG-3' B 5'-GTAGAGTGCAACAACACTGG-3'}

Os ciclos de temperatura foram testados e ajustados, para a reação, com base nas análises prévias de temperatura de anelamento proposto pelos seguintes autores: Pinder et al. (1991); Bonifácio et al. (2001); Angiolillo, et al. (2002); Lien et al. (1993); Sulimova et al. (2007a); Osta et al. (1995); Medrano \& Aguilar-Cordova (1990); Udina al. (2001); Mitra et al. (1995). O ciclo utilizado para a reação está apresentado a seguir.

Para conferir os produtos de amplificação do PCR, foi realizada eletroforese em gel de agarose $2 \%$. O tamanho dos fragmentos amplificados foi estimado utilizando-se, como marcador, fragmentos de pesos moleculares conhecidos (50pb DNA ladder - SAMBROOK et al., 1989; BERGER \& KIMMEL, 1987); em seguida, foi realizada a foto documentação.

A reação de corte do DNA amplificado com a enzima de restrição HindIII para kappa-caseína (ANGIOLILLO et. al., 2002) foi realizada com um volume final de $15 \mu$ l. Para cada reação foi preparada uma mistura contendo $8,5 \mu \mathrm{l}$ de água ultra pura, 1,0 $\mu 1$ de tampão da enzima, $0,5 \mu l$ (3 unidades) das enzimas de restrição, que foram homogeneizadas 
Rev. Bras. Saúde Prod. Anim., Salvador, v.16, n.1, p.- jan./mar., $2015 \quad$ http://www.rbspa.ufba.br ISSN 15199940

através de vórtex por $1 \mathrm{mim}$. Adicionou-se $10 \mu \mathrm{l}$ da mistura em um tubo para PCR contendo $5 \mu l$ do DNA amplificado (produto de PCR) por 4 horas a $37^{\circ} \mathrm{C}$, em condições de tamponamento; em seguida à digestão, foi realizada a inativação da enzima conforme recomendação do fabricante, sendo a HindIII a $80^{\circ} \mathrm{C}$ por $20 \mathrm{~min}$. Após a digestão enzimática, o DNA digerido foi analisado em gel de agarose a $2 \%$, com marcador de peso molecular DNALadder 50bp, corado com brometo de etídeo, visualizado em luz ultravioleta e fotografado, para verificação dos alelos.

Tabela 1. Descrições das etapas da PCR

\begin{tabular}{lcc}
\hline Etaps & Temperatura & Tempo \\
\hline Passo 1 (Desnaturação inicial) & $95^{\circ}$ & $5: 00 \mathrm{~min}$ \\
Passo 2 (Desnaturação) & $97^{\circ}$ & $0: 15 \mathrm{~min}$ \\
Passo 3 (Anelamento) & $56^{\circ}$ & $1: 00 \mathrm{~min}$ \\
Passo 4 (Extensão das fitas) & $72^{\circ}$ & $1: 30 \mathrm{~min}$ \\
Passo 5 (10 repetições dos passos 2 a 4) & - & - \\
Passo 6 (Desnatuação) & $95^{\circ}$ & $0: 30 \mathrm{~min}$ \\
Passo 7 (Anelamento) & $56^{\circ}$ & $1: 00 \mathrm{~min}$ \\
Passo 8 (Extensão das fitas) & $72^{\circ}$ & $1: 30 \mathrm{~min}$ \\
Passo 9 (25 repetições dos passos 6 a 8) & - & - \\
Passo 10 (Extensão final) & $72^{\circ}$ & $10: 00$ min \\
Passo 11 (Final) & $4^{\circ}$ & $\infty$ \\
\hline
\end{tabular}

Para os resultados de polimorfismo foram utilizadas análises descritivas e de dispersão de frequências. As amostras foram agrupadas pelo grupo genético dos animais. As frequências dos alelos dos genes em estudo foram calculadas por meio de contagem direta. Foram estudadas as frequências perante o teorema do equilíbrio de HardyWeinberg, tanto para cada grupo genético, quanto para o conjunto de todos os animais.

\section{RESULTADOS E DISCUSSÃO}

As amplificações dos alelos CSN3 da kappa-caseína com os primers específicos forward: 5' GTGCTGAG(T/C)AGGTATCCTAG 3' e revers: 5, GTAGAGTGCAACAACACTGG 3', apresentaram o mesmo padrão de amplificação com 1000 pb (Figura 1).
Quando os fragmentos amplificados dos DNAs foram digeridos com a enzima de restrição Hind III, a uma temperatura de $37^{\circ} \mathrm{C}$ durante 4 horas, apresentaram polimorfismo característico de cada raça.

Os resultados dos cortes da ação enzimática, para os três cruzamentos estudados, apresentaram maior frequência dos alelos A e B, como já constatado em outros trabalhos (PINDER et al.,1991, TSIARAS et al., 2005, UFFO et al., 2006, COMIN et al., 2008; OTAVIANO, 2006) porém também foi observado o alelo $\mathrm{C}$, como mostra a Figura 2.

As frequências genotípicas e alélicas foram estimadas por contagem simples dos genótipos visualizados na eletroforese obtida com o uso da técnica de PCRRFLP (Figura 1) e os padrões de migração se repetiram evidenciando a detecção do polimorfismo. As frequências obtidas para esta região do gene da kappa-caseína nos animais 
avaliados nesse estudo estão descritas na Tabela 2.

As frequências genotípicas esperadas de acordo com o teorema de HardyWeinberg foram 0,55 para o genótipo AA, 0,29 para o genótipo $\mathrm{AB}$, e 0,04 para o genótipo $\mathrm{BB}, 0,02$ para $\mathrm{o}$ genótipo $\mathrm{CC}$, 0,007 para o genótipo $\mathrm{BC}$,
0,09 para o genótipo AC. Quando se comparou as frequências observadas com as esperadas pelo teste Quiquadrado, ao nível de significância de 0,05 , pode-se afirmar que a população geral encontra-se em desequilíbrio, assim como os animais $5 / 8$.

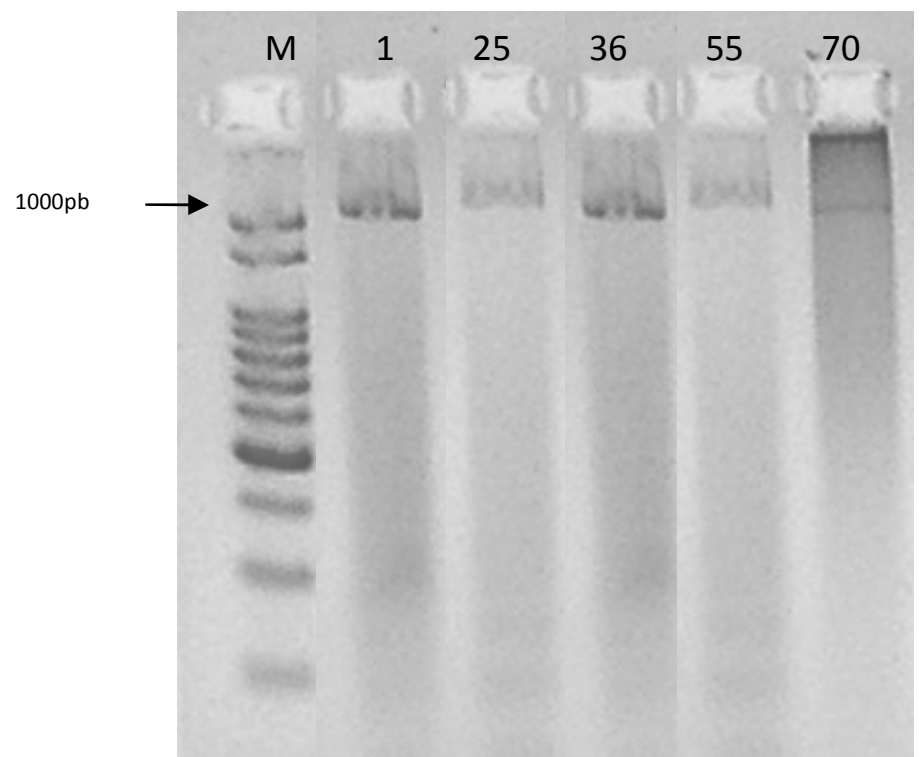

Figura 1. Fragmento de DNA amplificado (1000pb), contendo a região do gene kappa-casein exons 3-5 da k-caseína bovina, M: Marcador DNALadder 50bp, 1 e 55 animais $1 / 2 \mathrm{H}, 25$ e 70 animais $5 / 8 \mathrm{H}$ e 36 animal $3 / 4 \mathrm{H}$

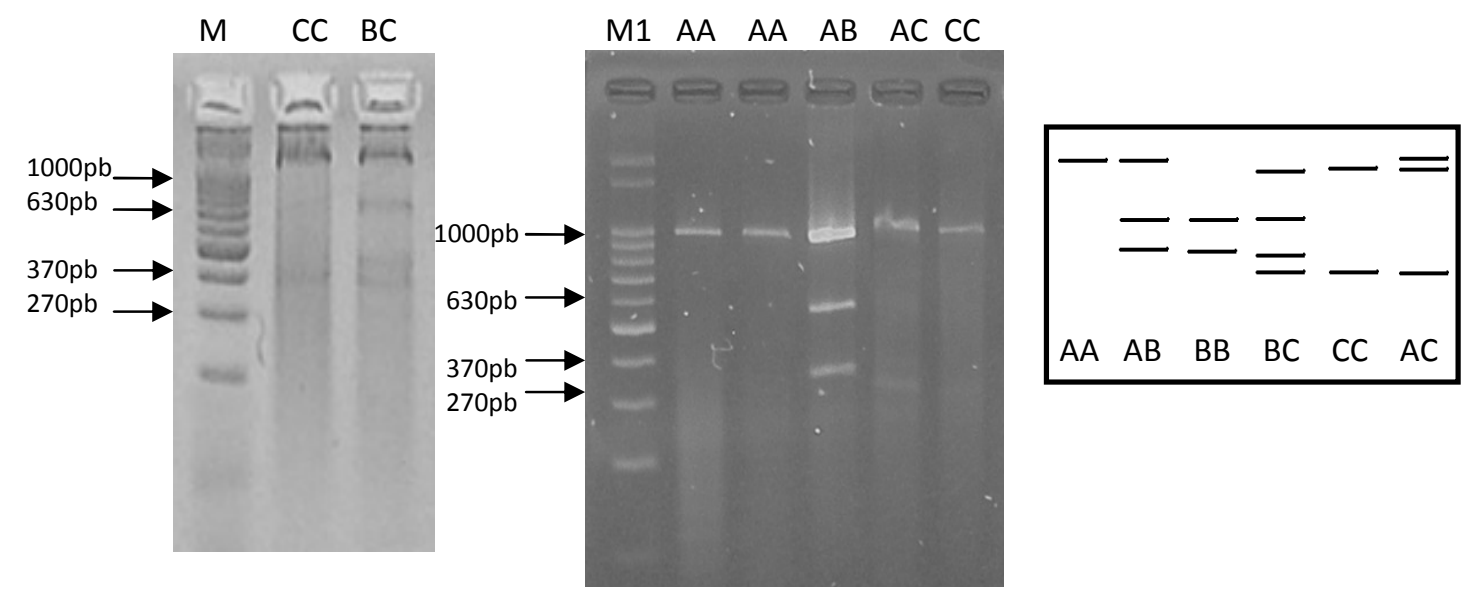

Figura 2. Genotipagem em bovinos da kappa-caseína, usando a reação em cadeia de polimerase (PCR) seguido pela ação da enzima de digestão Hind III. M: Marcador de 50pb e M1: Marcador de 100pb 
Rev. Bras. Saúde Prod. Anim., Salvador, v.16, n.1, p.- jan./mar., $2015 \quad$ http://www.rbspa.ufba.br ISSN 15199940

Tabela 2. Distribuição das frequências alélicas e genotípicas dos animais Holando-Gir $(1 / 2,5 / 8$ e $3 / 4)$ e de Qui-quadrado $(\mathrm{p}<0,05)$ para as frequências genotípicas

\begin{tabular}{|c|c|c|c|c|c|c|c|c|c|c|}
\hline \multirow[b]{2}{*}{ Frequências } & \multicolumn{3}{|c|}{ Alélicas } & \multicolumn{6}{|c|}{ Genotípicas } & \multirow{2}{*}{$\chi^{2}$} \\
\hline & A & B & $\mathrm{C}$ & AA & $\mathrm{AB}$ & BB & $\mathrm{BC}$ & $\mathrm{CC}$ & $\mathrm{AC}$ & \\
\hline $1 / 2$ & 0,73 & 0,20 & 0,07 & 0,53 & 0,33 & 0,03 & 0,00 & 0,03 & 0,07 & 6,93 \\
\hline $5 / 8$ & 0,74 & 0,22 & 0,04 & 0,66 & 0,14 & 0,13 & 0,04 & 0,01 & 0,01 & $31,09^{*}$ \\
\hline $3 / 4$ & 0,75 & 0,17 & 0,08 & 0,58 & 0,26 & 0,03 & 0,03 & 0,03 & 0,08 & 2,99 \\
\hline Geral & 0,74 & 0,20 & 0,06 & 0,59 & 0,25 & 0,06 & 0,02 & 0,02 & 0,05 & $26,08^{*}$ \\
\hline
\end{tabular}

O fato de a população geral estar em desequilíbrio é consequência do resultado apresentado pelos animais 5/8. Entretanto, é possível afirmar que esse desequilíbrio é aleatório. A proposta da estação experimental de chegar aos $5 / 8 \mathrm{HG}$ fez com que alguns tourinhos tivessem a preferência na utilização dos cruzamentos e isso pode ter influenciado as diferentes frequências genotípicas nas populações. Já os grupos genéticos $1 / 2$ e $3 / 4$ estão em equilíbrio sugerindo que os grupos tende a permanecer com a mesma distribuição se não houver interferência externa.

As frequências obtidas de 0,74 , para o alelo A, e 0,20, para o alelo B, estão próximas das encontradas por Pinder et al. (1991), quando estudavam animais Holandeses. O mesmo foi verificado por Uffo et al. (2006), em animais crioulos de Cuba, que também demonstraram que em animais da raça Siboney, as frequências variaram de 0,7 a 0,8 , para o alelo A, e de 0,2 a 0,3, para o alelo B. No entanto, em nenhum desses trabalhos foi identificado o alelo $\mathrm{C}$. Além disso, em trabalho realizado com vacas Holandesas de linhagem italiana (COMIN et al., 2008), os alelos A e B também foram os mais observados, porém nesse mesmo estudo os autores observaram, também, o alelo E mesmo que com uma baixa frequência $(0,06)$.

Por outro lado, os dados encontrados nesse estudo discordam dos encontrados por Tsiaras et al. (2005) que identificaram em vacas holandesas a frequência de 88,5, para o genótipo AA, e 11,5 para o $A B$, não encontrando o genótipo BB. Segundo Sulimova et al. (2007b), o genótipo BB é o mais importante para a fabricação de queijos devido as propriedades do coalho desse tipo específico de leite. Já Postiglioni et al. (2002) encontraram uma maior frequência para o genótipo $\mathrm{AB}$, de 0,5 , e 0,25 para o genótipo AA; já para o genótipo $\mathrm{BB}$ foi relatada uma frequência de 0,24, o que no caso desse último genótipo se apresenta como uma melhor ocorrência de leite para a fabricação de queijo.

Otaviano (2006) realizou um experimento com diferentes raças de bovinos e os valores encontrados para o gado holandês foi o que mais se aproximou com os observados no presente estudo, encontrando 0,62 para o genótipo AA, 0,26 para $\mathrm{AB}$ e 0,12 para $\mathrm{BB}$, também não encontrando o alelo $\mathrm{C}$.

A baixa frequência do genótipo $\mathrm{BB}$ também foi encontrada em outros estudos em diversos países como Pinder et al. (1991), no Reino Unido, Tsiaras et al. (2005), na Grécia, Uffo et al. (2006), em Cuba, Comin et al. (2008), na Itália, e Otaviano (2006), no Brasil, o que concorda com a frequência desse genótipo observada no rebanho estudado. Outra característica que é possível de relacionar com os alelos A e B da k-Cn é a produção de leite. Lin et al. (1989) verificaram que vacas com genótipo BB apresentam produção superior as de 
Rev. Bras. Saúde Prod. Anim., Salvador, v.16, n.1, p.- jan./mar., $2015 \quad$ http://www.rbspa.ufba.br ISSN 15199940

genótipo $\mathrm{AA}$ e $\mathrm{AB}$, em animais das raças Holandesa, Ayrshire e seu cruzamento. Em contraste, Gonyon et al. (1987) observaram efeito significante oposto onde vacas Holandesas AA apresentaram, em média, $180 \mathrm{~kg}$ a mais de leite do que vacas BB. Bovenhuis et al. (1992) demonstraram que vacas com genótipo $\mathrm{BB}$ produziam $173 \mathrm{~kg}$ menos de leite do que vacas com genótipo AA. Por outro lado, outros pesquisadores como Aleandri et al (1990); McLean et al. (1987) e McLean et al. (1984) relataram que não há efeito de cada alelo na produção de leite.

Os resultados possibilitaram identificar polimorfismos pouco encontrados na literatura, as formas $\mathrm{CC}, \mathrm{AC}$ e $\mathrm{BC}$ do gene da kappa-caseína. Dessa forma recomenda-se futuros estudos para uma avaliação mais detalhada desses grupamentos genéticos.

A presença do genótipo $\mathrm{BB}$ na população de vacas holando-gir em regiões de Pernambuco, bem como a frequência do alelo B, é um resultado muito importante, uma vez que esse genótipo interfere positivamente no processamento do leite. Esse resultado indica a implantação de programas de seleção genética visando aumento na frequência do genótipo em questão, o que possibilitará ganhos significativos na cadeia do leite, particularmente, produtores e indústrias de processamento.

\section{AGRADECIMENTOS}

Ao $C N P q$ e à FACEPE pelo financiamento da pesquisa. Ao IPA pela cessão dos dados.

\section{REFERÊNCIAS}

ALEANDRI, R.; BUTTAZZONI, L.G.; SCHNEIDER, J.C. The effects of milk polymorphism on milk components and cheese producing ability. Journal of Dairy Science, v.73, n.2, p.241-255, 1990.

ALEXANDER L.J.; STEWART A.F.; MACKINLAY A.G.; KAPELINSKAYA T.V.; TKACH T.M.; GORODETSKY S.L. Isolation and characterization of the bovine K-casein gene. European Journal of Biochemistry, v.178, n.2, p.395-401, 1988.

ANGIOLILLO, A.; YAHYAOUI, M. H.; SÁMCHES, A.; PILLA, F.; FOLCH, J. $M$. Characterization of a new genetic variant in the caprine k-casein gene.

Journal of Dairy Science, v.85, n.10, p.2679-2680, 2002.

BERGER, S.L.; KIMMEL, A.R. Methods in enzymology, volume 152: guide to Molecular Cloning Techniques. New York: Academic Press, 1987. 812p.

BONIFÁCIO, C.; SANTOS, I.C.; BELO, C.; CRAVADOR, A. Single-strand conformation polymorphism (sscp) analysis of $\alpha$ s1-casein genes in Charnequeira Portuguese indigenous goat breed. Archivos de Zootecnia, v.50, n.189/190, p.105-111, 2001.

BOVENHUIS H.; JOHAN, A. M.; ARENDONK, V.; KORVER, S.

Association between milk protein polymorphisms and milk production traits. Journal of Dairy Science, v.75, n.9, p.2549-2559, 1992.

COMIN, A.; CASSANDRO, M.; CHESSA, S.; OJALA, M.; DAL ZOTTO, R.; DE MARCHI, M.; CARNIER, P.; GALLO, L.; PAGNACCO, G.; BITTANTE, G. Effects of composite $\beta$ - and $\kappa$-casein genotypes on milk coagulation, quality, and yield traits in Italian Holstein cows. Journal of Dairy Science, v.91, n.10, p.4022-4027, 2008. 
Rev. Bras. Saúde Prod. Anim., Salvador, v.16, n.1, p.- jan./mar., $2015 \quad$ http://www.rbspa.ufba.br ISSN 15199940

ERHARDT, G.; SENFT, B. Integration of milk protein variants in bovine breeding programmes using an economical screening method. Animal Genetics, v.20, n.1, p.61, 1989.

GARCIA, J.F. Micromanipulação, criopreservação e sexagem pela técnica de PCR (polymerase chain reaction) de embriões bovinos. Tese (Doutorado) Faculdade de Medicina Veterinária e Zootecnia, Universidade de São Paulo, 1995.

GONYON, D.S.; MATHER, R.E.;

HINES, H.C. Association of bovine blood and milk polymorphisms with lactation traits: Holsteins. Journal of Dairy

Science, v.70, n.12, p.2585-2598, 1987.

LIN, C.Y.; McALLISTER, K.F.; NGKWAIHANG, K.F. Relationships of milk protein types to lifetime performance. Journal of Dairy Science, v.72, n.11, p.3085-3090, 1989.

\section{LIEN S.; KAMINSKI S.; ALESTRON}

P.; ROGNE S. A simple and powerful method for linkage analysis by amplification of DNA from single sperm cell. Genomics, v.16, n.1, p.41-44, 1993.

MANIATIS, T.; FRITSCH, E.F; SAMBROOK, J. Molecular cloning a laboratory manual. New York: Cold Spring Harbor Laboratory Press, 1989.

McLEAN, D.M.; GRAHAM, E.R.; PONZONI, R.W. Effects of milk protein genetic variants on milk yield and composition. Journal of Dairy Research, v.51, n.4, p.531-546, 1984.

McLEAN, D.M.; GRAHAM, E.R.; PONZONI, R.W. Effects of milk protein genetic variants and composition on heat stability of milk. Journal of Dairy Research, v.54, n.2, p.219-235, 1987.
MEDRANO, J.F.; AGUILAR-

CÓRDOVA, E. Polymerase chain reaction amplification of bovine $\beta$ lactoglobulin genomic sequences and identification of genetic variants by RFLP analysis. Animal Biotechnology, v.1, n.1, p.73-77, 1990 .

MITRA, A.; SCHLEE, P.;

BALAKRISHNAN, C.R. Polymorphisms at growth hormone and prolactin loci in Indian cattle and buffalo. Journal Animal Breeding and Genetics, v.112, n.1/6, p.71-74, 1995.

OTAVIANO, A.R.; LIMA, A.L.F.; LAUREANO, M.M.M.; SENA, J.A.D.; ALBUQUERQUE, L.G.; TONHATI, H. $\beta$-casein gene polymorphism permits identification of bovine milk mixed with bubaline milk in mozzarella cheese.

Genetics and Molecular Biology, v.31, n.4, p.902-905, 2008.

OSTA, R.; GARCÍA-MURO, E.;

ZARAZAGA, I. A MspI polymorphism at the bovine alpha-lactalbumin gene.

Animal Genetics, v.26, n.3, p.204-205, 1995.

PINDER, S.J.; PERRI, B.N.; SKIDMORE, C.J.; SAVVA, D. Analysis of polimorphism in the bovine casein genes by use if the polymerase chain reaction. Animal Genetics, v.22, n.1, p.11-20, 1991.

POSTIGLIONO, A., RINCON, G., KELLY, L., LLAMBI, G., FERNANDEZ, G., D`ANGELO, M., GAGLIARDI, G., TRUJILLO, J., BETHENCOURT, M., GUEVARA, K., CASTELLANO, A., ARRUGA, M. V. Biodiversidad genética en bovinos criollos del Uruguay, análisis con marcadores molecular. Archivos de Zootecnia, v.51, n.194, p.195-202, 2002. 
Rev. Bras. Saúde Prod. Anim., Salvador, v.16, n.1, p.- jan./mar., $2015 \quad$ http://www.rbspa.ufba.br

RACHAGANI, S.; GUPTA I.D.; GUPTA, N.; GUPTA, S.C. Genotyping of $\beta$-lactoglobulin gene by PCR-RFLP in Sahiwal and Tharparkar cattle breeds. BMC Genetic, v.7, p.31-34, 2006.

SAMBROOK, J., FRITSCH, E.F., MANIATIS, T. Molecular Cloning: A Laboratory Manual. New York: Cold Spring Harbor Laboratory Press, 1989.

SULIMOVA G.E.; ABANI AZARI, M.; ROSTAMZADEH, J.; MOHAMMAD ABANI, M.R.; LAZEBNYI, O.E. Allelic polymorphism of kappa-casein gene (CSN3) in Russian cattle breeds and its informative value as a genetic marker. Genetika, v.43, n.1, p.88-95, 2007a.

SULIMOVA G.E.; ABANI AZARI, M., ROSTAMZADEH, J.; MOHAMMAD ABANI, M.R.; LAZEBNYI, O.E. K-casein gene (CSN3) allelic polymorphism in Russian cattle breeds and its information value as a genetic marker.

Russian Journal of Genetics, v.43, n.1, p.73-79, $2007 b$.

TSIARAS A. M., BARGOULI G. G., BANOS G. BOSCOS, C.M. Effect of kappa-casein and beta-lactoglobulin loci on milk production traits and reproductive performance of Holstein cows. Journal of Dairy Science, v.88, n.1, p.327-334, 2005.

UDINA, I.G.; TURKOVA, S.O.;

KOSTYUCHENKO, M.V.; LEBEDEVA, L.A.; SULIMOVA, G.E. Polymorphism of bovine prolactin gene: Microsatellites, PCR-RFLP. Russian Journal of Genetics, v.37, n.4, p.407411, 2001.
UFFO, O.; MARTÍN-BURRIEL, I., MARTÍNEZ, R.; RONDA. R.; OSTA, R.; RODELLAR, C.; ZARAGOZA, C. Caracterización genética de seis proteínas lácteas en tres razas bovinas cubanas. Animal Genetics Resources Information, v.39, p.15-24, 2006.

Data de recebimento: 22/10/2014 Data de aprovação: 04/03/2015 